Y/SM-34

\title{
NEW AND EMERGING TECHNOLOGIES FOR REAL-TIME AIR AND SURFACE BERYLLIUM MONITORING
}

\section{SEPTEMBER 2001}

B. E. Phifer, Jr.

E. L. Churnetski

L. E. Cooke

J. J. Reed

M. L. Howell

V. D. Smith

Prepared by the

Oak Ridge Y-12 National Security Complex

P.O. Box 2009

Oak Ridge, Tennessee 37831

Operated by

BWXT Y-12, L.L.C.

for the

U.S. Department of Energy

under Contract DE-AC05-00OR22800 
This report was prepared as an account of work sponsored by an agency of the United States Government. Neither the United States Government nor any agency thereof, or any of their employees, makes any warranty, expressed or implied, or assumes any legal liability or responsibility for the accuracy, completeness, or usefulness of any information, apparatus, product, or process disclosed, or represents that its use would not infringe privately-owned right. Reference herein to any specific commercial product, process, or service by trade name, trademark, manufacturer, or otherwise does not necessarily constitute or imply its endorsement, recommendation, or favoring by the United States Government or any agency thereof. The views and opinions of authors expressed herein do not necessarily state or reflect those of the United States Government or any agency thereof. 
Y/SM-34

\title{
New and Emerging Technologies for Real-Time Air and Surface Beryllium Monitoring
}

\author{
September 2001
}

\author{
$\underline{\text { Y-12 National Security Complex }}$ \\ B. E. Phifer, Jr. \\ E. L. Churnetski \\ L. E. Cooke \\ John Reed
}

Oak Ridge National Laboratory

M. L. Howell

\section{$\frac{\text { Pro2Serve Technical Solutions }}{V . D m i t h}$

\author{
V. D. Smith
}

\author{
Prepared by the \\ Oak Ridge Y-12 National Security Complex \\ P.O. Box 2009 \\ Oak Ridge, Tennessee 37831 \\ Operated by \\ BWXT Y-12, L.L.C. \\ for the \\ U.S. Department of Energy \\ under Contract DE-AC05-00OR22800
}




\section{Contents}

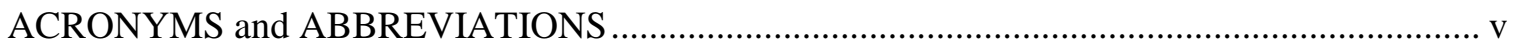

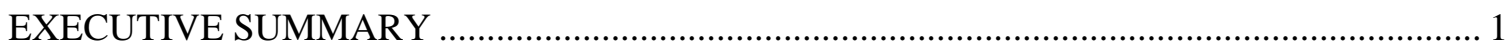

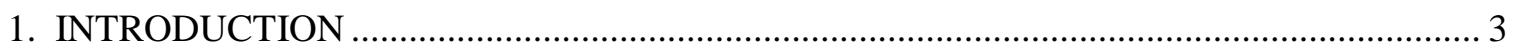

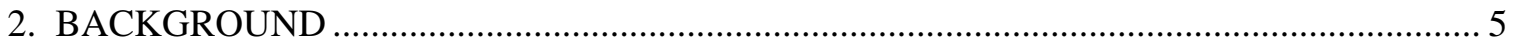

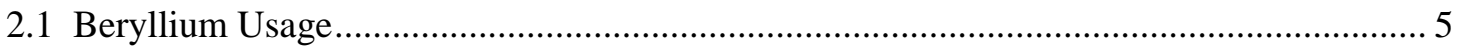

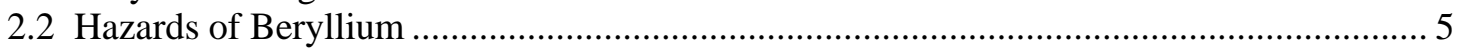

2.3 History, Current Monitoring Practices, and Future Use of Beryllium at DOE .................. 6

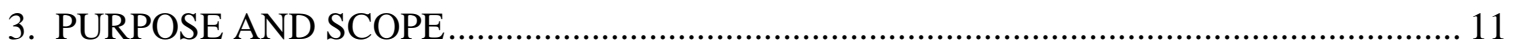

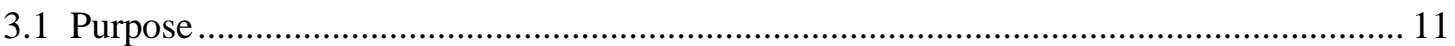

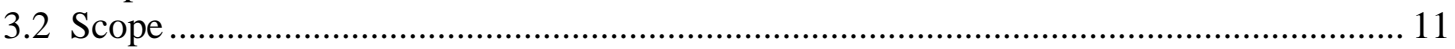

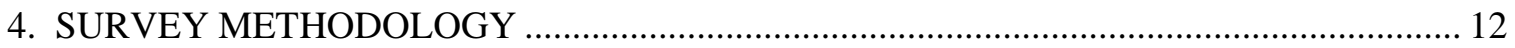

5. DISCUSSION

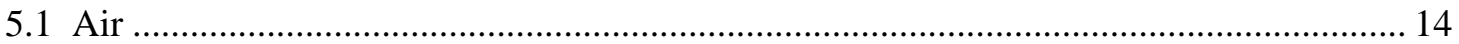

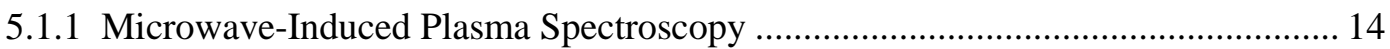

5.1.2 Aerosol Beam-Focused Laser-Induced Plasma Spectroscopy ................................ 16

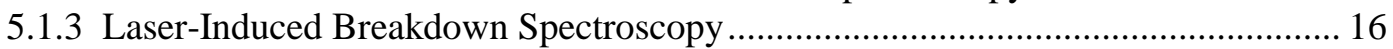

5.1.4 Surfaced-Enhanced Raman Scattering Spectroscopy............................................ 18

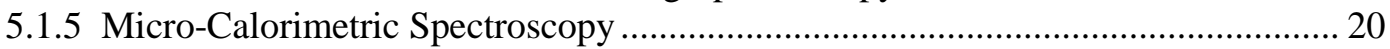

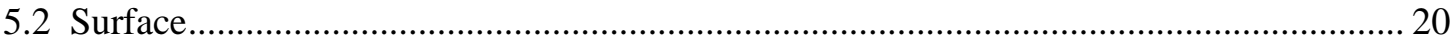

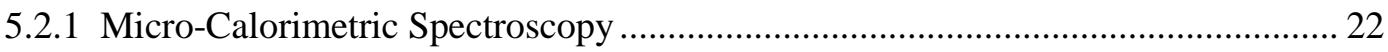

5.2.2 Microwave-Induced Plasma Spectroscopy …....................................................... 22

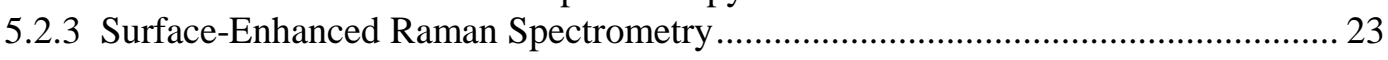

5.2.4 Laser-Induced Breakdown Spectroscopy ............................................................ 23

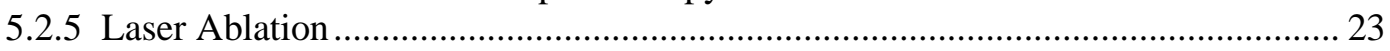

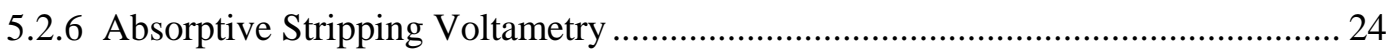

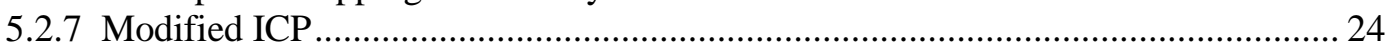

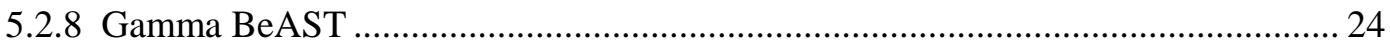

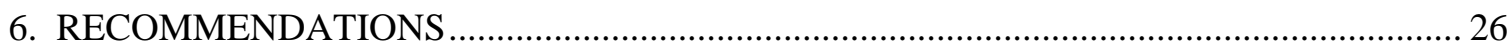

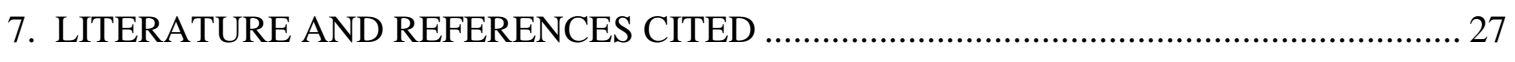

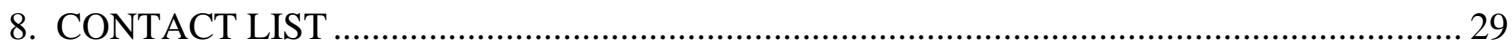





\section{ACRONYMS and ABBREVIATIONS}

$\begin{array}{ll}\text { ABFLIPS } & \text { aerosol beam-focused laser-induced plasma spectroscopy } \\ \text { AES } & \text { atomic emission spectroscopy } \\ \text { ASO } & \text { Analytical Services Organization } \\ \text { ASV } & \text { absorptive stripping voltametry } \\ \text { Be } & \text { beryllium } \\ \text { BeO } & \text { beryllium oxide } \\ \text { CalSpec } & \text { micro-calorimetric spectroscopy } \\ \text { CBD } & \text { chronic beryllium disease } \\ \text { CBDPP } & \text { chronic beryllium disease prevention program } \\ \text { D\&D } & \text { decontamination and decommissioning } \\ \text { DIMP } & \text { diisopropyl methylphosphonate } \\ \text { DMMP } & \text { 2-mercaptorthanol } \\ \text { DOE } & \text { Department of Energy } \\ \text { EPA } & \text { U.S. Environmental Protection Agency } \\ \text { HSA } & \text { homogeneous sampling area } \\ \text { ICP } & \text { inductively coupled plasma spectroscopy } \\ \text { IR } & \text { infrared } \\ \text { LANL } & \text { Los Alamos National Laboratory } \\ \text { LIBS } & \text { laser-induced breakdown spectroscopy } \\ \text { MIPS } & \text { microwave-induced plasma spectroscopy } \\ \text { Nd/YAG } & \text { neodymium/yttrium-aluminum-garnet } \\ \text { NIOSH } & \text { National Institute for Occupational Safety and Health } \\ \text { NIR } & \text { near infrared } \\ \text { OES } & \text { optical emission spectroscopy } \\ \text { OSHA } & \text { Occupational Safety and Health Administration } \\ \text { PEL } & \text { permissible exposure limit } \\ \text { SERS } & \text { surface-enhanced Raman scattering } \\ \text { TLV } & \text { threshold limit value } \\ \text { TNT } & \text { trinitrotoluene } \\ \text { TWA } & \text { time weighted average } \\ & \\ & \end{array}$




\section{EXECUTIVE SUMMARY}

On January 7, 2000, the Department of Energy (DOE) published 10CFR 850 - Chronic Beryllium Disease Prevention Program (CBDPP) Final Rule, which lowered the 8-hour time weighted average action level from 0.5 to $0.2 \mathrm{ug} / \mathrm{m}^{3}$. The final rule implements a CBDPP to decrease the exposure to beryllium and to significantly reduce the incidence rate of chronic beryllium disease (CBD). Since a cure for CBD does not exist, occupational sampling and monitoring are critical in the assessment of worker exposure. Current methods for monitoring airborne particulates are costly, time-consuming, and labor-intensive. Subsequently, there is a real need for real-time air and surface monitoring to enhance worker protection and reduce the incidence rate of CBD.

In this study, five emerging technologies were identified for real-time monitoring of airborne beryllium: Microwave-Induced Plasma Spectroscopy (MIPS), Aerosol Beam-Focused LaserInduced Plasma Spectroscopy (ABFLIPS), Laser-Induced Breakdown Spectroscopy (LIBS), Surfaced-Enhanced Raman Scattering (SERS) Spectroscopy, and Micro-Calorimetric Spectroscopy (CalSpec). Desired features of real-time air beryllium monitoring instrumentation were developed from the Y-12 CBDPP. These features were used as guidelines for the identification of potential technologies as well as their unique demonstrated capability to provide real-time monitoring of similar materials. However, best available technologies were considered, regardless of their ability to comply with the desired features. None of the five technologies have the capability to measure the particle size of airborne beryllium. Although reducing the total concentration of airborne beryllium is important, current literature suggests that reducing or eliminating the concentration of respirable beryllium is critical for worker health protection.

Eight emerging technologies were identified for surface monitoring of beryllium. CalSpec, MIPS, SERS, LIBS, Laser Ablation, Absorptive Stripping Voltametry (ASV), Modified Inductively Coupled Plasma (ICP) Spectroscopy, and Gamma BeAST. Desired features of real-time surface beryllium monitoring were developed from the Y-12 CBDPP. These features were used as guidelines for the identification of potential technologies. However, the best available technologies were considered regardless of their ability to comply with the desired features.

The following recommendations should be considered when evaluating potential technologies for field-testing:

1. Invest in technologies that have a high potential for performing both air and surface monitoring capabilities.

2. Utilize desired features listed in Table 1 and Table 2 for air and surface monitoring to evaluate new and emerging technologies.

3. Identify additional limitations and confounding variables and other possible metal interferences, for example titanium, and add to Tables 1 and 2.

4. Perform additional studies to determine if the technology could be further developed to include the capability to measure the particle size of airborne beryllium.

5. Perform additional studies to determine industrial workplace contaminants which can mask or interfere with surface monitoring, such as dust, grease, and oils. 


\section{INTRODUCTION}

Beryllium has been used for many years in support of the Department of Energy's (DOE's) mission. During beryllium processing, beryllium aerosol particulates and beryllium material are generated. Documented illnesses of chronic beryllium disease (CBD) have occurred over the years in individuals who worked in and around beryllium. Workers with incidental exposures to beryllium have developed CBD. New and more protective regulations and requirements have been implemented to reduce or minimize the levels of beryllium exposure and therefore reduce the risks to workers health and safety. Occupational sampling and monitoring are critical in the assessment of worker exposure.

The existing method of measuring the concentration of beryllium in air requires collection of beryllium oxide aerosols on filters and beryllium material on dry wipes followed by laboratory dissolution and analysis. The time required for analysis of air samples is 24 hours or longer, and analysis of surface samples can take 7 or more days. In contrast, successful development of a field portable device that is easy to operate could augment, if not replace, this traditional beryllium assessment technology to measure beryllium in air and/or on surfaces. There is a great need for a real-time air and surface monitoring capability to enhance worker protection and reduce the incidence rate of $\mathrm{CBD}$.

Development of an instrument that detects beryllium in real-time will not only benefit the health and safety of workers and DOE, but it will impact and revolutionize the entire beryllium industry. The greatest benefit of this new technology is that it increases the health and safety of beryllium workers (i.e., you know what the beryllium contamination levels are before the exposure), resulting in a reduced incidence rate of CBD. Real-time beryllium monitoring can

- Provide instant analyses of beryllium samples in the field instead of taking a sample and sending it to a laboratory, where it may take days to get the results.

- Decrease the time and costs of characterizing the workplace.

- Replace traditional, obsolete, and aging beryllium exposure assessment technology with innovative, agile manufacturing techniques and processes.

- Reduce the time and cost currently required to collect, transport, and analyze samples.

- Reduce cleaning, material, and handling costs.

- Reduce beryllium laboratory and personal protective equipment waste streams with improved segregation techniques.

- Improve the recruiting of workers and retention of essential personnel by indicating what potential beryllium exposure levels are in real-time, thus easing their anxiety about exposure and effect. 
- Allow immediate feedback (i.e., effective training) to operators and show what the effect of their operation techniques and work habits have on the levels of beryllium generated (i.e., improved housekeeping, minimize cross-contamination, etc.). 


\section{BACKGROUND}

\subsection{Beryllium Usage}

The United States is the world's leading producer, processor, and consumer of beryllium products (Department of Energy 1999). Beryllium is used primarily by the aerospace, defense, and nuclear weapons industry because of its high tensile strength, light weight, and high resistance to corrosion. One major source of beryllium usage is nuclear weapons production. Consequently, beryllium has been used by DOE for the production of nuclear weapons, nuclear reactor moderator reflectors, and as nuclear reactor fuel cladding since the 1940s.

At DOE, beryllium operations have historically included melting, casting, grinding, and machine tooling of parts (Department of Energy 1999). Beryllium process technology is $>20$ years old and requires multiple-step grinding processes to produce powder, consolidating the powder into block, and direct machining of components from the pressed block. Typical machining operations were performed with lathes, mills, saws, and deburring tools.

\subsection{Hazards of Beryllium}

The primary hazard associated with beryllium processing is the inhalation of beryllium dust. Inhalation of beryllium dust or particles can cause CBD or beryllium sensitization. Furthermore, beryllium and its compounds are listed as A2, suspected human carcinogens. Beryllium has been classified by the National Institute for Occupational Safety and Health (NIOSH) as a potential carcinogen, and the International Agency for Research on Cancer and the American Conference of Government Industrial Hygienists have also identified beryllium as a human carcinogen.

Beryllium sensitization occurs when the body produces antibodies in response to beryllium exposure. Workers with beryllium sensitization are at an increased risk of developing CBD. (Renberger, D.L., Hewitt, E.R. Initial Beryllium Characterization Report, Fluor Daniel Hanford, Richland, WA, September 29, 1999). CBD is a chronic, often debilitating and sometimes fatal, lung condition.

CBD is a chronic disorder of the lungs following the inhalation of beryllium, which causes an immune response to occur, and is cell-mediated. CBD results from a hypersensitivity reaction to beryllium (Stange et al. 1996) that enters the body primarily through inhalation of beryllium dusts, mists, or fumes. Exposure to beryllium causes lung disease in 2 to $6 \%$ of all workers in industries where airborne beryllium is generated (National Jewish Medical and Research Center 1998). This rate rises greatly to $\sim 10$ to $14 \%$ for occupations such as machinists in beryllium operations (U.S. Department of Energy 2000). With CBD, the lungs suffer from inflammation and scarring, which makes it more difficult for the lungs to transport oxygen to the bloodstream and body. Symptoms of CBD include shortness of breath, dry cough, chest pain, fatigue, weight loss, and loss of appetite (U.S. Department of Energy 2000). In many cases, these symptoms may not appear for several years, or even decades, after exposure. Typical disease latency is $\sim 20$ years, but can range from 1 to 30 years. CBD cannot be cured; however, treatment with steroids 
provides some control of the progression of the disease by reducing the buildup of scar tissue and delaying permanent lung damage (U.S. Department of Energy 2000).

The inhalation toxicity of beryllium may occur through acute or chronic exposures. Short-term exposures to beryllium at high levels have been reported to cause acute beryllium disease. These short-term exposures may cause (1) acute responses that include inflamed and swollen lungs and (2) conditions such as pulmonary edema and chemical pneumonitis. These conditions usually occur 1 to 2 weeks after exposure. Long-term exposure to beryllium or beryllium oxide has been reported to cause $\mathrm{CBD}$, characterized by shortness of breath, scarring of the lungs, and berylliosis (noncancerous growths in the lungs of humans) (National Jewish Medical and Research Center 1998). Both acute and chronic beryllium disease can be fatal, depending on the severity of the exposure (Agency for Toxic Substances and Disease Registry 1998).

When inhaled, the metal or its insoluble salts are deposited in the lung and appear to be slowly absorbed and excreted. Beryllium can be found in the urine of workers up to 10 years after the exposure to beryllium has ceased. Small doses are deposited in the bone. Large doses are deposited in the liver and are slowly mobilized to bone (National Medical Services 1997). Small particles or chips of insoluble beryllium-containing materials break off during machining and other processes and can be spread through the air in the work area.

\subsection{History, Current Monitoring Practices, and Future Use of Beryllium at DOE}

Exposure to airborne beryllium dust is the only known cause of CBD. The first reported evidence of the existence of CBD was reported in 1946. In 1949, the Atomic Energy Commission, the predecessor to DOE, established a $2-\mu \mathrm{g} / \mathrm{m}^{3}$ regulation to protect workers from exposure to beryllium. In 1971, the Occupational Safety and Health Administration (OSHA) adopted a Permissible Exposure Limit (PEL) of $2 \mu \mathrm{g} / \mathrm{m}^{3}$ 8-hour Time Weighted Average (TWA), which was codified in 29 CFR 1910.1000 . From the $1970 \mathrm{~s}$ to the mid-1980s, the $2 \mu \mathrm{g} / \mathrm{m}^{3}$ was thought to be protective of worker health because of the decrease in the number of CBD cases. However, in 1987, a new CBD case at Rocky Flats generated renewed scrutiny of the beryllium action level. In 1989, the first new non-occupational case in 30 years of CBD was reported. This led to DOE issuing DOE Notice 440.1, Interim Chronic Beryllium Disease Prevention Program, signed by Secretary Pena. In December 1999, DOE published 10 CFR Part 850 CBDPP, Final Rule, establishing $0.2 \mu \mathrm{g} / \mathrm{m}^{3}$ 8-hour TWA action level in the worker's breathing zone. From 1991, when DOE instituted the medical surveillance program for current and former workers, until June 2000, approximately 400 workers were sensitized to beryllium and 140 were diagnosed with CBD (St. Louis Post-Dispatch June 2000). As a result of the reemergence of CBD among DOE workers, DOE established the Final Rule in 10 CFR Part 850, Chronic Beryllium Disease Prevention Program. The timeline of beryllium usage, CBD occurrence, and beryllium regulations are shown in Fig. 1.

Current practices for air and surface monitoring include industrial hygiene monitoring in work areas comprised of permanent air sampling and smear sampling. These programs include permanent, fixed-head, strategically placed air samplers; routine weekly surface contamination smears; and nonroutine smears for upset or special-need conditions. Workplace air monitoring is used to evaluate employee exposures to beryllium. 

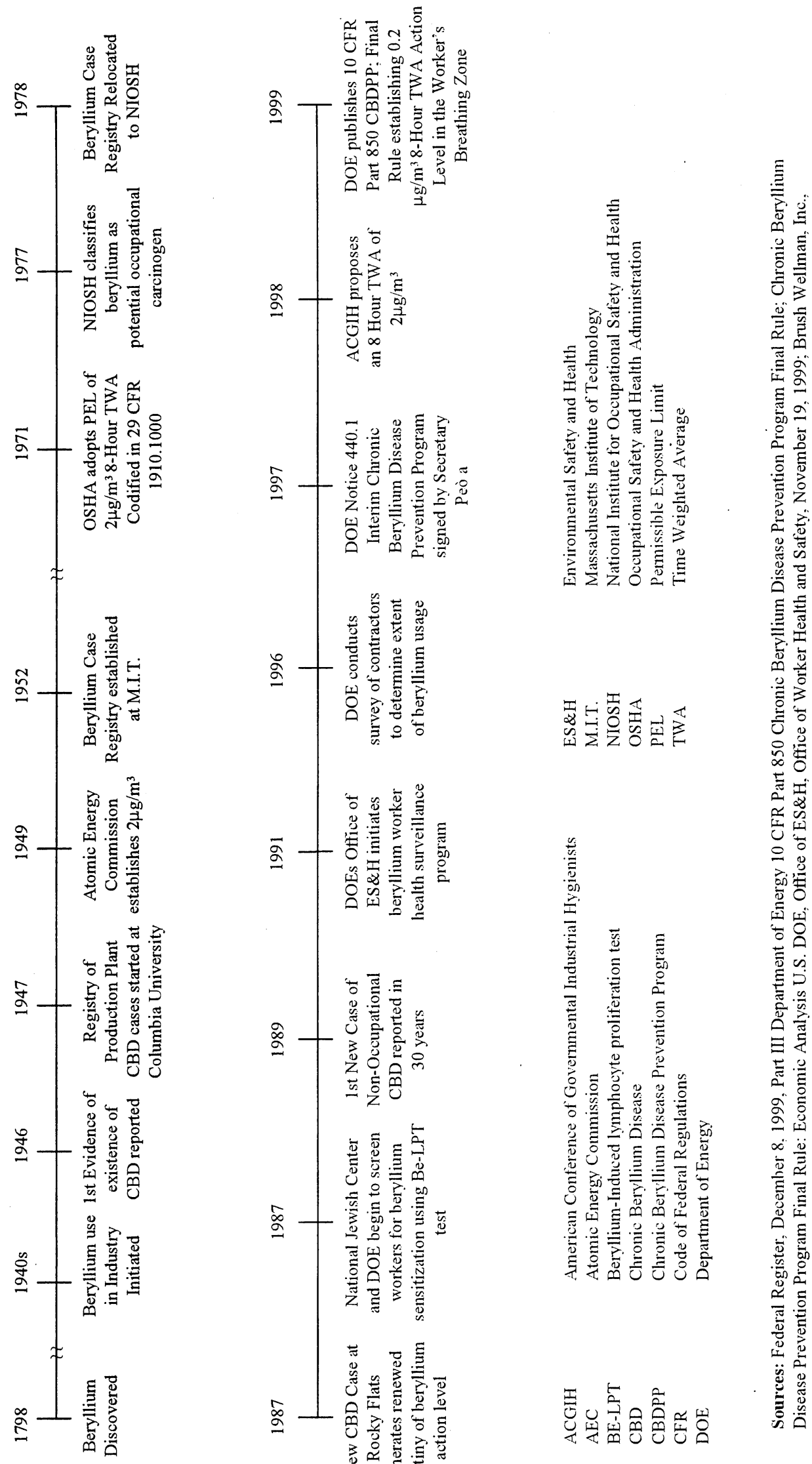

施

을



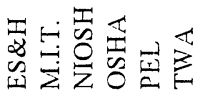
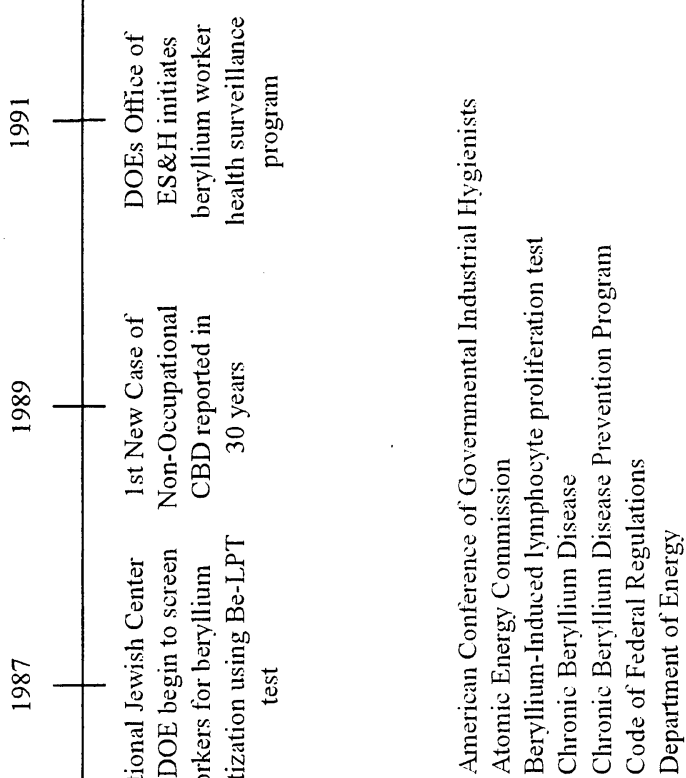

竞

哠

至

贾

要

菅

员

氙

哇空

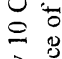

䆛题

武 동

응

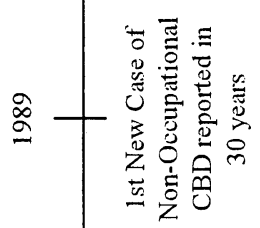

$\xi$

苞蓄

手安它

总

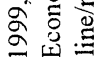

$\infty$ i.

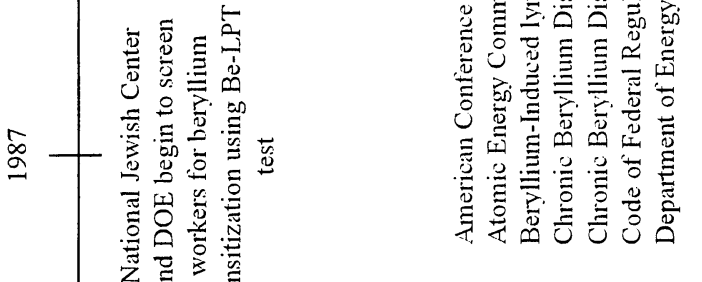

㐫

政

岂活

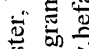

然定

语产

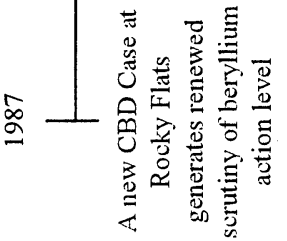

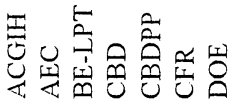

In 
Personal air monitoring is used to evaluate exposure of individual workers. Area air monitoring is used to evaluate background and general workplace concentrations of beryllium. A disadvantage of current air monitoring techniques is the delay between the time of sample collection and the time of sample analysis. At one DOE installation, the delay is 24 hours for laboratory analytical air monitoring results and reporting. Beryllium concentrations are not known until the results of the sample analysis are reported, which causes a delay in the evaluation and correction of any unacceptable condition. Other problems include the labor-intensive process, which contains many points of failure or bias in collecting, averaging, integrating, and calculating the exposure of an individual worker in an industrial environment.

In addition, current literature reports that the proposed TLV of $0.2 \mu \mathrm{g} / \mathrm{m}^{3}$ based solely on total mass of beryllium may not be protective of human health or appropriate. A TLV based on particle size and the chemical form of beryllium is more likely to protect workers from sensitization and CBD. Results reported by Michael Kent, manager of industrial hygiene for Brush Wellman, Inc., indicate that industrial processes that generate beryllium particles which are $<0.5 \mu \mathrm{m}$ in diameter are capable of being deposited in the alveolar region of the lung and create a higher incidence of CBD. In addition, research has indicated that certain chemical compositions, such as beryllium oxide and metallic beryllium, are more toxic than beryllium alloys and other forms (Miller 1999).

Before discussing current practices for surface sampling, surface contamination must be defined. Surface contamination is described as removable contamination in 10 CFR Part 850, Subpart A, 850.3. Removable contamination means beryllium contamination that can be removed by casual wiping, brushing, and washing. The definition for removable contamination is taken from the U.S. DOE Radiological Control Manual (DOE/EH-0256T Revision 1, April 1994).

Current practices for sampling surfaces include using a wet sampling method. 10 CFR Part 850, Subpart C, 850.30 states where beryllium is present in the operational areas of DOE facilities, the responsible employer must conduct routine surface sampling to determine housekeeping conditions. Surfaces contaminated with beryllium dusts and waste must not exceed a removable contamination level of $3 \mu \mathrm{g} / 100 \mathrm{~cm}^{2}$ during non-operational periods. This will facilitate the exposure monitoring as required by 10 CFR 850 Subpart C, 850.24. In the Final Rule, the only method recommended by DOE is the wet method for conducting surface sampling. DOE refrained from mandating a particular method to conduct surface sampling. DOE recommends but does not mandate a particular method to conduct the surface sampling. DOE recommends NIOSH Method 9100 (NIOSH 1994). DOE acknowledges that this may have to be modified for surfaces smaller than $100 \mathrm{~cm}^{2}$. Surface sampling procedures for beryllium detection from the Brush Wellman Company, Inc., the Los Alamos National Laboratory (LANL), and Rocky Flats can be accessed at the following internet site, http://www.eh.doe.gov/be/itk.html-ssi, (as of September $28,2000)$, for more detailed information on current practices of beryllium surface sampling.

Although the exposure zone for air sampling is well defined as the worker's breathing zone, the exposure area for surface sampling is less well defined. Therefore, identification of surface sample locations, such as homogeneous sampling areas (HSAs), is of paramount importance for conducting surface sampling for beryllium. Biased sample locations include the following:

$\underline{\text { HSA }}$

Floor

\section{Biased Sample Location}

Corner of room where dust accumulates

Under an object not routinely cleaned

Traffic area traversed by beryllium workers

Adjacent to equipment associated with beryllium 

Ceiling
On top surface above beryllium processing area
On top surface of frame
On top surface where dust accumulation is noted
Adjacent to exhaust ventilation system
Adjacent to supply ventilation system

\begin{abstract}
Process On top surfaces where dust accumulates
equipment On hidden surfaces not routinely cleaned

On internal components

Oily area where dust tends to cling

Internal Back of shelf area

areas

Under cabinet drawer

Back of cabinet shelf

Internal parts of non-process equipment

HVAC Dead areas where dust tends to accumulate

system On access flanges where dust accumulates

On upper surfaces of vent louvers

At intakes potentially impacted by other exhausts

Within plenum where dust accumulates

Oily areas within plenum

Oily areas associated with motor and/or blower

Local Dead areas where dust tends to accumulate

exhaust On access flanges where dust accumulates

ventilation On upper surfaces of vent louvers

systems

Downstream of filter where dust accumulates

Within plenum where dust accumulates

Oily areas within plenum

Oily areas associated with motor and/or blower
\end{abstract}

Misc.

Doorjambs

horizontal

Elevated windowsills

surfaces

On top of duct work (external)

On top of piping, bus bars, and other building components

On top of girders and other structural members (Rocky Flats Environmental Technology Site, February 3, 1997).

Although biased sampling locations may be easy to define, beryllium has been detected in unsuspected areas on machine equipment. In August 2000, beryllium was found on Y-12 grinding wheels and prompted a facility-wide recall of grinding wheels used at the Y-12 Plant. This action followed an employee's discovery in July 2000 that grinding wheels utilized in Building 9201-1 machine shops might contain 0 to $2 \%$ of a beryllium alloy.

After investigating the matter, officials determined that $\sim 9$ grinding wheels contained very low levels of beryllium aluminum silicate. Grinding operations ceased temporarily because of current 
health concerns over beryllium sensitization and the existence of CBD among some Y-12 employees.

Analytical services laboratory personnel examined 430 smears for beryllium, and only 9 of those smears showed any detectable beryllium, which were below regulatory guidelines for surface contamination. Only two of the nine were above the free release limit. Following an Industrial Hygiene assessment, the area in question was put back in operation (Parson 2000).

Although machining is one of the primary uses of beryllium, a number of DOE operations create beryllium dust: (1) machining beryllium or beryllium parts, (2) manufacturing beryllium parts, (3) processing beryllium parts, (4) laboratory use of beryllium parts, (5) industrial hygiene work related to beryllium monitoring, (6) decontamination and decommissioning (D\&D) berylliumcontaminated workplaces, and (7) maintenance or housekeeping in beryllium-contaminated workplaces (U.S. Department of Energy November 1999).

Although DOE is de-emphasizing the nuclear weapons program, which is the major source for beryllium use, the Department does expect the pace of beryllium-related work to increase in the near future. First, DOE expects to continue using beryllium in its industrial, aerospace, and research and development projects because the combination of properties beryllium offers in these applications are not easily replaced by other metals or materials. Second, DOE has begun to decommission facilities that are no longer needed to support the Department's mission. Facilities that are decommissioned must also be decontaminated before they are demolished or converted to other uses. These D\&D projects will increase in the near future as surplus facilities are taken offline (Office of Environmental Management 1996). Several of the facilities slated for D\&D are contaminated with beryllium, creating the potential for harmful exposure among D\&D workers. The continued use of beryllium in industrial and aerospace applications, combined with the increased pace of D\&D work, will increase the number of operations that present the potential for worker exposure to beryllium in the near future (U.S. Department of Energy, November 1999). Worker exposure through the inhalation of these tiny beryllium particles can lead to CBD.

Since there is no known medical cure for CBD, new and emerging technologies are focusing on preventive measures, real-time monitoring, and early detection in order to decrease worker exposure to airborne beryllium dust. 


\section{PURPOSE AND SCOPE}

\subsection{Purpose}

The purpose of this report is to identify new and emerging technologies that have potential for providing real-time beryllium air and surface monitoring.

\subsection{Scope}

With the resurgence of beryllium disease and federal government pressure to reduce exposure to beryllium, it is critical that technology assessments and evaluations be performed to implement state-of-the-art sampling, monitoring, and exposure control systems to reduce the exposure and risks of CBD. According to the previous Energy Secretary, Bill Richardson, a potential compensation program for workers in the nation's nuclear weapons plants was long overdue given the risks of their work. The compensation plan will allow workers to claim lost wages and medical and rehabilitation costs for illnesses linked to their exposure to beryllium while working at nuclear bomb factories and nuclear production facilities. The compensation plan is expected to cost about $\$ 13$ million a year over the next ten years (Hebert 1999). Based on the new and more protective regulations and requirements, characterization of air particles has become even more important than ever for environmental research and occupational safety. These drivers clearly indicate an urgent need to develop, test, and implement effective methods and technologies for air particulate monitoring in real-time.

Direct-reading or real-time air monitoring instrumentation performs both sampling and measurement and provides almost immediate results. For those chemicals where instrumentation has been developed, real-time monitoring provides cost-effective and timely characterization of the workplace.

The scope of this report is limited to identifying new and emerging technologies that are capable of developing real-time beryllium air and surface monitoring. 


\section{SURVEY METHODOLOGY}

Technologies were identified through literature searches, communication with researchers at Oak Ridge National Laboratory, researchers located at other national labs, and a review of the subject matter found on the Internet.

Tables 1 and 2 list the desired features of real-time beryllium monitoring instrumentation, which were developed from the Y-12 CBDPP. These features were used as guidelines for the identification of potential technologies. Many of the technologies are still under development and, therefore, testing of desired parameters has yet to be performed and verified. However, the best available technologies were considered, regardless of their ability to comply with the desired features.

Table 1. Desired features for real-time beryllium air monitoring instrument

- Digital readout display in $\mu \mathrm{g} / \mathrm{m}^{3}$ (three significant figures)

- Minimum detection level $0.05 \mu \mathrm{g} / \mathrm{m}^{3}$ or best available

- Measurement range 0.05 to $1000 \mu \mathrm{g} / \mathrm{m}^{3}$

- 15-min or less response time

- Measurement accuracy $\pm 10 \%$ or best available

- Low-level zero drift to provide stability and prevent false readings

- Capability of logging, storing, printing, and downloading measurements to a computer application

- Capability of operating in humidity from 0 to $95 \%$

- Capability of operating at a minimum temperature of 32 to $100^{\circ} \mathrm{F}$

- Capability of self-test to indicate when instrument is not in working order

- Transportable size for field measurements

- Capability of correcting for metal interferences commonly found in the nuclear industry $(\mathrm{Ca}, \mathrm{Al}, \mathrm{Fe}, \mathrm{V}, \mathrm{Sn}, \mathrm{W}$, etc.)

- Capability of correcting for memory interference from last sample 


\section{Table 2. Desired features for real-time beryllium surface monitoring instrument}

- Digital readout display in $\mu \mathrm{g} / \mathrm{m}^{2}$ (three significant figures)

- Minimum detection level $0.05 \mu \mathrm{g} / \mathrm{m}^{2}$ or best available

- Measurement range 0.05 to $1000 \mu \mathrm{g} / \mathrm{m}^{2}$

- Daily calibration

- 10 -s response time (exposure to display)

- Measurement accuracy $\pm 3 \%$

- Low-level zero drift to provide stability and prevent false readings

- Capability of logging, storing, printing, and downloading measurements to computer applications

- Capability of operating in humidity from 0 to $95 \%$

- Capability of operating at a minimum temperature of 0 to $100^{\circ} \mathrm{F}$

- Transportable size for field measurements

- Rechargeable with a battery life of $8 \mathrm{~h}$

- Capability of self-test to indicate when instrument is not in working order

- Capability of measuring beryllium contamination on smooth to very rough surfaces

- Capability of correcting for metal interferences commonly found in the nuclear industry $(\mathrm{Ca}, \mathrm{Al}, \mathrm{Fe}, \mathrm{V}, \mathrm{Sn}, \mathrm{W}$, etc.)

- Capability of correcting for memory interference from last sample 


\section{DISCUSSION}

\subsection{Air}

Five current or near-term technologies were identified that have demonstrated or have the potential capability to monitor and detect real-time beryllium air exposure. The five technologies include Microwave-Induced Plasma Spectroscopy (MIPS), Aerosol Beam-Focused Laser Induced Plasma Spectroscopy (ABFLIPS), Laser-Induced Breakdown Spectroscopy (LIBS), SurfacedEnhanced Raman Scattering (SERS) Spectroscopy, and Micro-Calorimetric Spectroscopy (CalSpec). SERS spectroscopy and CalSpec technologies are laboratory bench-scale configurations that have not been demonstrated for beryllium monitoring. As a result, the desired features from Table 1 cannot be applied due to the lack of maturity of the technology. The identification of each of these potential technologies was based on their capability to provide realtime monitoring of materials similar to beryllium. Two of the technologies, MIPS and LIBS, are more advanced and have been developed into prototype instruments. However, these prototypes have not been field tested. Therefore, testing of the desired parameters listed in Table 1 has yet to be performed and verified.

None of the five technologies have the capability to measure the particle size of airborne beryllium. Although reducing the total concentration of airborne beryllium is important, current literature suggests that reducing or eliminating the concentration of respirable beryllium is most important for worker health protection. In addition, the MIPS and LIBS prototype instruments have not been shown to have the capability of detecting other chemical compositions such as beryllium oxide $(\mathrm{BeO})$ or beryllium compounds. The ABFLIPS, SERS, and CalSpec technologies only address the demonstrated capability to detect $\mathrm{BeO}$.

All technologies previously listed use some type of spectroscopy. Spectroscopy is the qualitative or quantitative study of molecules, which utilizes absorption, emission, or scattering of electromagnetic radiation. Spectroscopy can also be used to study physical processes. The interaction of radiation with these molecules can cause a change in the direction of the radiation and, in turn, can cause transitions between the energy levels of the atoms or molecules. Absorption is the transition from a lower level to a higher level with the transfer of energy to the molecule. Emission is the transition from a higher energy level to a lower energy level if energy is transferred to the radiation field (Tissue 1996). Scattering is the redirection of light due to its interaction with molecules. Scattering may or may not occur with the transfer of energy; therefore, the scattered radiation produces a slightly different wavelength or the same wavelength (Tissue 1996).

\subsubsection{Microwave-Induced Plasma Spectroscopy}

Description - MIPS uses microwave-induced plasma in conjunction with atomic emission spectroscopy(AES). Microwave-induced plasmas are powerful sources for element analysis. Microwave-induced plasma consists of a quartz tube surrounded by a microwave cavity that serves as a waveguide (Fig. 2). Microwaves produced from a microwave generator fill the cavity and cause the electrons in the plasma support gas to oscillate. The oscillating electrons collide with other atoms in the flowing gas. A spark is needed to create some initial electrons in order to form the plasma. The result is a high-temperature plasma that is created and maintained. Atomic emission is measured from the excited atoms as they exit the microwave cavity (Tissue 1996). 


\section{MIPS}

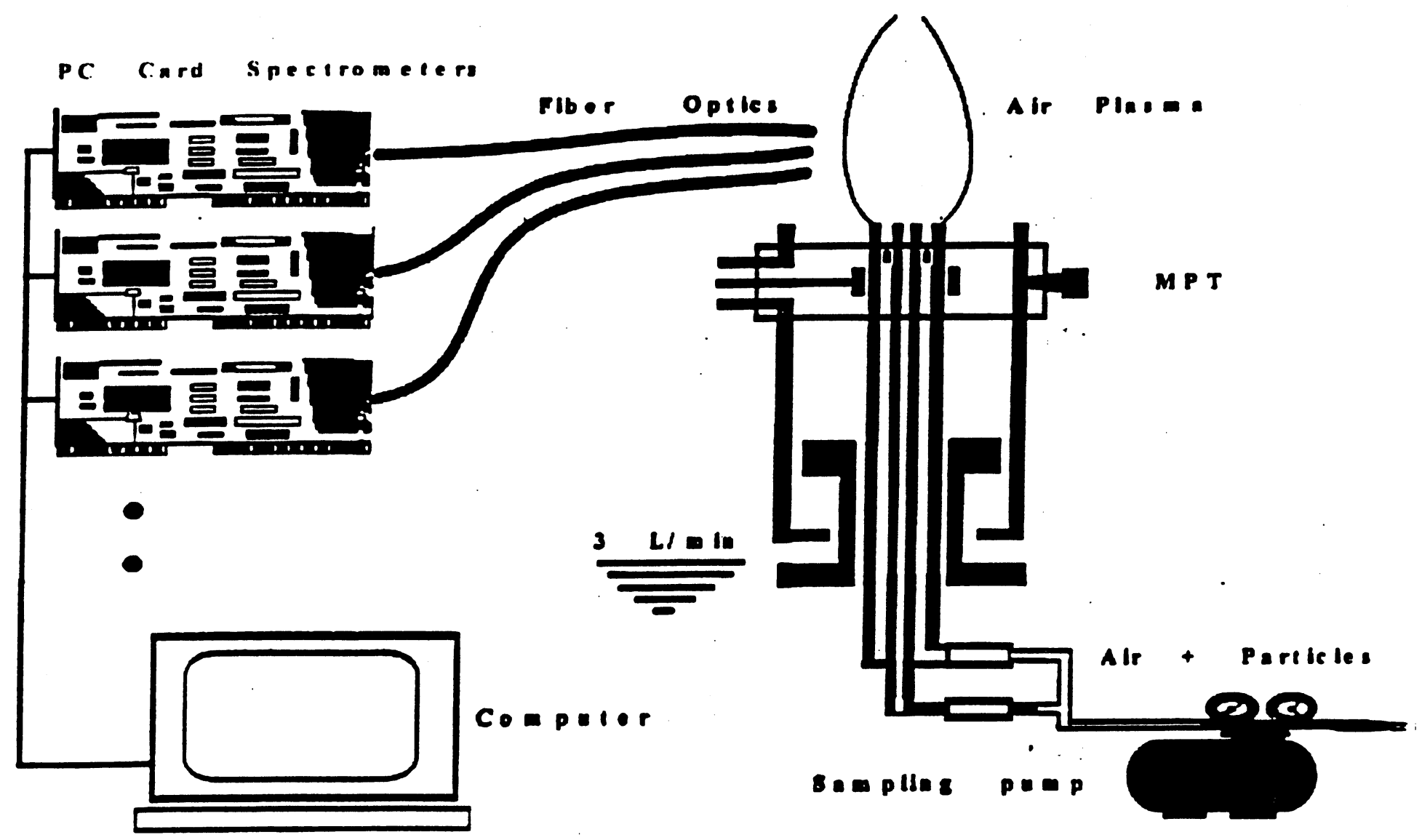

Fig. 2. MIPS schematic. 
AES or optical emission spectroscopy (OES) uses quantitative measurement of the optical emission from excited atoms to determine the concentration. The atoms in solution are promoted into high-energy levels by the use of a flame, discharge, or plasma. The atoms decay and, therefore, go back to lower levels by emitting light. The emission lines in the spectra are narrow because the transitions are between distinct atomic energy levels. The major advantage of AES is that all atoms in a sample are excited simultaneously and can be detected simultaneously (Tissue 1996).

Status -As of August 2000, MIPS was currently in the form of a laboratory bench-scale model at LANL. Researchers and developers were actively pursuing funding to convert the bench-scale model to a field portable device so that testing of beryllium particles of variable sizes could be tested and analyzed (Abeln 2000). Testing has previously been performed on beryllium samples. The technology appears to be robust and possesses sufficient sensitivity to form the basis of a field instrument. Based on Ed Churtnetski's review of the MIPS technology, one option that needs to be further investigated is replacing the current ICP-OES system currently under development by the Y-12 Plant with the MIP microwave plasma torch with a suitable detector. This could have both operational and economic advantages over the current ICP.

\subsubsection{Aerosol Beam-Focused Laser-Induced Plasma Spectroscopy}

Description - ABFLIPS is the second and newest technique that measures a given element by drawing an aerosol sample through a shaped nozzle. The aerosol particles are converged to the focal point of the light of a neodymium/yttrium-aluminum-garnet (Nd/YAG) laser. The convergence greatly increases the localized particle-number concentration at the focal point; thus, enhancing detection. When airborne particles are heated by a high-energy laser pulse, a microplasma is produced at the focal point which partially vaporizes those particles and causes a fraction of the constituent elements to become electronically excited. The element of interest emits light at characteristic wavelengths. If no other elements are present that have emissions at a wavelength close enough to interfere, the measured intensity of light at the characteristic wavelength will be directly related to the concentration of the element of interest in the sampled air.

Status - As of August 2001, ABFLIPS technology was in development. ABFLIPS received Plant Directed Research, Development, and Demonstration (PDRD) funding in FY 2001 to evaluate this technology for detection of airborne beryllium particles at the Y-12 Complex. The technical goals of the project will explore techniques to increase instrument sensitivity, investigate the relationship between particle size and sensitivity, choose wavelengths for beryllium detection, and test and determine the effectiveness of the monitor. The project is scheduled for completion by October 2004.

\subsubsection{Laser-Induced Breakdown Spectroscopy}

Description - LIBS is the third technology that was identified and evaluated for its usefulness in continuously monitoring toxic metals, such as beryllium. LIBS uses a laser as an ionization source to cause dielectric breakdown to create a hot plasma (Fig.3). The energy from this plasma can excite the molecules, which radiates the atomic lines characteristic of the material sample. AES is used to analyze the light emission from the plasma (Tissue 1996). 


\section{LIBS}

\section{Principle of Operation}

\section{Sampie inie:}

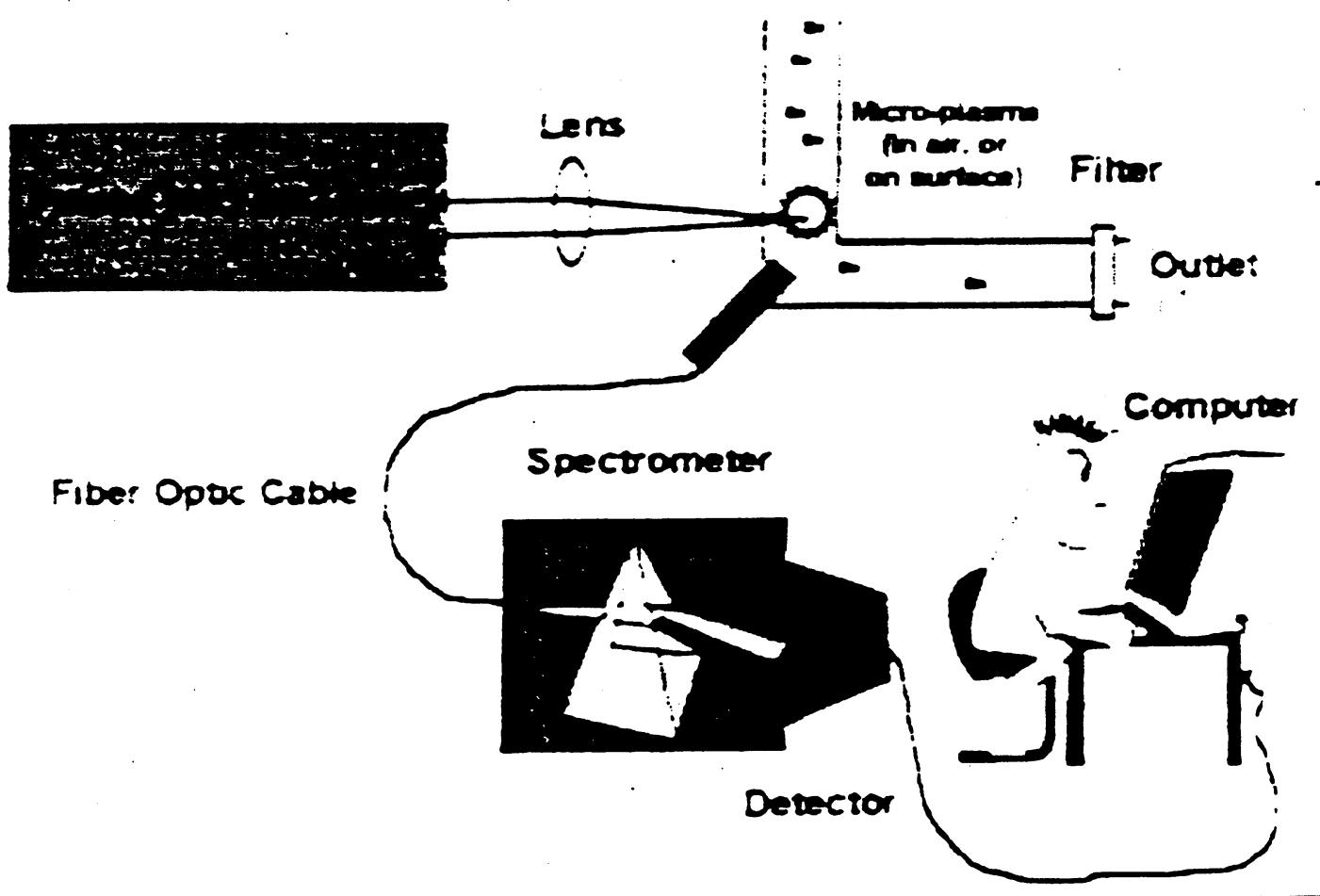

Fig. 3. Schematic of LIBS operation. 
Status - Additional studies need to be performed to evaluate the capability of improving the LIBS sensitivity and to determine if the instrument can correct for other interferences. For example, the spectrum for titanium is very close to that of beryllium. The Department of Energy Deactivation/Decommissioning Program funded a project for FY 2000 and FY 2001 to develop a real-time (or near-real-time) monitor for airborne beryllium. Their approach was to investigate the development of a reliable LIBS measurement technology for quantitative analysis on a filter substrate in the presence of common workplace dusts, mists, and fumes generated during D\&D activities. The results of this project could provide improvements in areas of sample efficiency, sampling volume size and sensitivity, stability of the LIBS signals, and detection limit. Based on the results of this initiative, a determination should then be made concerning field testing of a prototype LIBS instrument.

\subsubsection{Surfaced-Enhanced Raman Scattering Spectroscopy}

Description - SERS spectroscopy is the fourth technology that was identified and evaluated. Raman spectroscopy is the measurement of the wavelength and intensity of inelastically scattered light from molecules. Two molecular-scattering processes may occur when a molecule is irradiated with photons: elastic scattering and inelastic scattering. Elastic scattering involves no change in energy. This process is called Rayleigh scattering. Other collisions between these photons and the molecule may be inelastic. These collisions can cause the molecule to undergo a transition to a higher energy level. The photon that gives rise to this transition loses energy and is scattered with a lower frequency. The intensity profile within the range of frequencies in the scattered field is the Raman spectrum of the molecule being irradiated. Positive shifts are known as Stokes lines, and negative shifts are known as anti-Stokes lines. The overall Raman spectrum comprises a range of frequencies on either side of the Rayleigh line, which are mirror images of each other.

Raman technology employs a helium neon laser, acoustic-optic tunable filters, and a photo sensor to detect toxic chemicals, trinitrotoluene (TNT), and hundreds of chemicals (Fig. 4). An acousticoptic tunable filter is a solid-state optical bandpass filter that can be tuned to various wavelengths. Raman technology involves illuminating a sample with a laser beam and measuring the reflected light. The light shows the vibration energies, which are unique to each compound in the sample, and that information helps scientists identify the substance.

In $11 \mathrm{~s}$, the prototype instrument, dubbed RAMiTS (RAMan Tunable Integrated Sensor), provides a spectral analysis. The final product will translate that into a readout identifying the chemical or compound. Instead of taking a sample and sending it to a laboratory, where it may take days to get the results, this device will enable people to get an instant analysis of samples in the field.

This particular device has not yet been developed for the real-time quantitative measurement of chemicals in air, but it is feasible according to a recent technical review conducted by E. L. Churnetski of the Y-12 Technical Development Organization. 


\section{SERS}

\section{Raman Instrumental Setup}

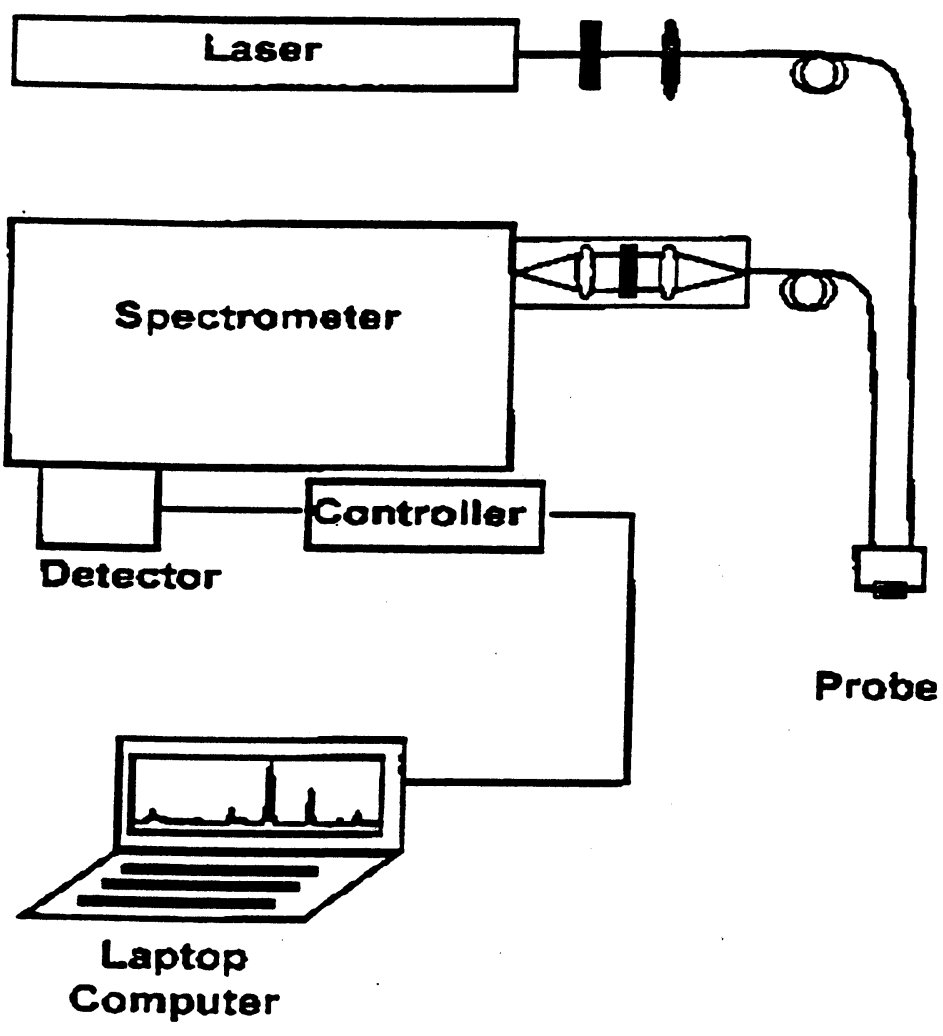

Fig. 4. Schematic of SERS. 
Status - As of August 2001, SERS technology was being tested in a laboratory bench-scale model and there are plans to explore the possibility of developing a field portable device. SERS has the potential to perform real-time air monitoring for beryllium. Funding is currently being sought at the Y-12 Complex to determine the feasibility of measuring $\mathrm{BeO}$ in the air. The feasibility studies will determine the unique signature for $\mathrm{BeO}$ using SERS. In addition to conducting the Raman measurements for $\mathrm{BeO}$, various SERS-active substrates will be tested to demonstrate the best combination of molecular diffusion and direct SERS detection for $\mathrm{BeO}$. These studies will also investigate the effect of various laser excitation wavelengths, as well as the use of gated detection. From these studies, calibration curves can be developed and sensitivity detection limits can be determined.

\subsubsection{Micro-Calorimetric Spectroscopy}

Description - CalSpec is the fourth and final technique that was researched. CalSpec is based on a differential temperature-absorption spectroscopy technique that obtains photothermal signature spectra for target chemicals. Ultra-sensitive micro-mechanical thermal detectors are used to detect target molecules in essentially real-time with a sensitivity of a parts-per-billion and identify them using their photothermal signature. This general technique is capable of detecting and identifying a variety of chemical species simultaneously and has been demonstrated with chemical warfare agent simulants, which include diisopropyl methylphosphonate (DIMP) and 2-mercaptorthanol (DMMP), explosives TNT, and other compounds. In this study, CalSpec used a microcantilever thermal detector (Fig. 5). The bending of the microcantilevers due to the absorption of photons can be determined by a number of methods, which include an optical readout technique. A laser was used in a probe configuration to monitor the microcantilever bending. The laser was focused onto the tip of the microcantilever using a $30 \mathrm{X}$ microscope objective. A neutral density filter was placed between the probe laser and the objective to minimize heating of the tip by the laser. A photodiode detector was used to collect the reflected beam from the probe. A digital oscilloscope was used to monitor and record the amplified signal from the photodiode (Datskos et al. 1997).

Status - As of August 2000, CalSpec had not been tested on an actual beryllium sample. A unique photothermal signature has not been obtained for $\mathrm{BeO}$. Based on comments by E. L. Churnetski, Y-12 Technical Development Organization, further studies would be needed to determine exact detection limits, specificity, and the capability of correcting for common metal interferences that are found in the industrial workplace. In addition, studies would be needed to explore the applicability to other beryllium-containing species other than the oxide, e.g., metallic beryllium, beryllium hydroxide, etc. It is questionable whether the technique could provide true volumetric/mass quantification for large (micron-sized) particles of $\mathrm{BeO}$ and how relatively large particles would be made to adhere to the detectors (Review of Research Proposal, E. L. Churnetski).

\subsection{Surface}

Eight new and emerging technologies have been identified with the potential for real-time surface monitoring. The technologies are CalSpec, MIPS, SERS, LIBS, Laser Ablation, Absorptive Stripping Voltametry (ASV), Modified inductively coupled plasma spectroscopy (ICP), and Gamma BeAST. Since most of the eight technologies identified as having the potential to conduct real-time surface monitoring have been described in Sect. 5.1, detailed descriptions of the technologies will not be repeated in this section. The list of desired features for beryllium realtime surface monitoring in Table 2 was utilized for all of the technologies. However, technologies were not excluded if they did not meet all the criteria listed in Table 2. Many of the technologies are still under development and, therefore, testing of desired parameters has yet to be performed and verified. 


\section{CALSPEC}

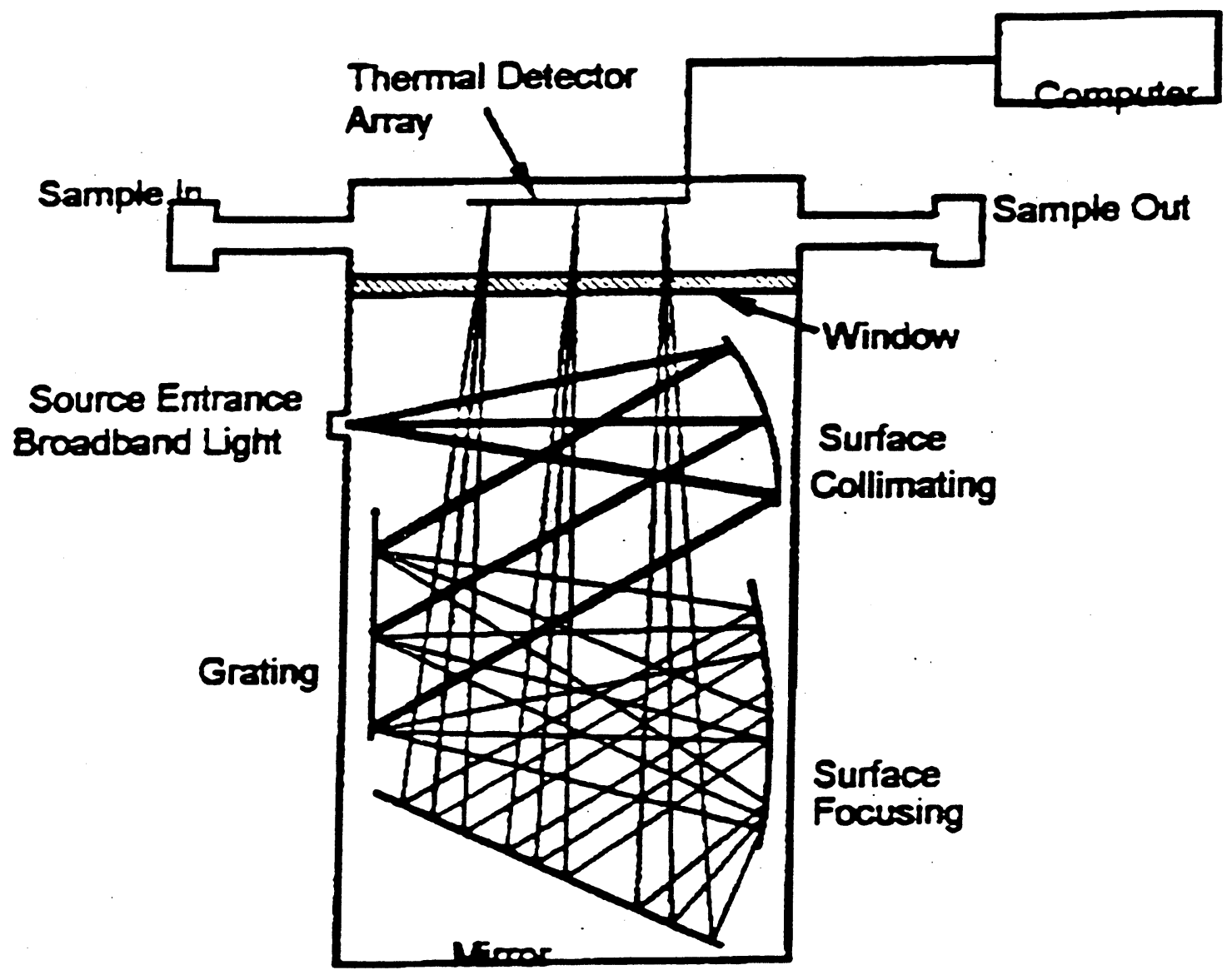

Fig. 5. CalSpec technique. 


\subsubsection{Micro-Calorimetric Spectroscopy}

Description - CalSpec measures the temperature differential of molecules in a sample resulting in a unique photothermal signature response which is displayed via wavelengths. Molecules are allowed to be absorbed onto thermal detectors. The temperature change of the thermal detectors are porportional to photon absorption. Since the thermal detectors will be exposed to different wavelengths, a very sensitive and unique photothermal signature response can be obtained. (Rajic, S. Datskos, P.G. Near-Real Time BeO Characterization Based on a Novel MicroCalorimetric Spectroscopy Technique). For a detailed description of the CalSpec technology please see Sect. 5.1.5.

Status - As of September 2000, researchers were developing a field portable hand-held device that can be used in the field for on-site monitoring. The next phase of development for CalSpec is a hand-held, laboratory box version and then a mini-instrument, which can be utilized for on-site monitoring. This technology is a 1998 R\&D 100 award winning technology which gives substantial credibility and merit to the research and development of this technology. As of August 2000, CalSpec had not been tested on an actual beryllium sample. The focus of CalSpec's research and development is real-time air monitoring. CalSpec may have the potential to do realtime surface monitoring; however, surface monitoring is not the focus of the research and development, and the result of an independent evaluation by Y-12 Development Division does not believe that Cal-Spec is applicable to surface monitoring applications.

The focus on CalSpec is real-time beryllium air monitoring and not real-time surface monitoring. Although the potential may exist to conduct real-time surface monitoring, the potential has yet to be explored.

\subsubsection{Microwave-Induced Plasma Spectroscopy}

Description - Please see Sect. 5.1.1 for a detailed description of MIPS.

Status - As of August 2000, MIPS was a laboratory bench-scale model. Researchers and developers were actively pursuing funding to convert the bench-scale model to a field portable device so that testing of beryllium particles of variable sizes could be tested and analyzed (Abeln 2000). Testing has previously been performed on beryllium samples.

This technology provides on-time continuous air monitoring without pre-treatment, portable and compact structure, low operating cost, and possibility of continuous operation without intervention. Testing has been performed on beryllium samples.

The technology does not lend itself to direct surface monitoring, nor is such an application claimed by the developers. However, there is reason to believe that the MIP microwave plasma torch with a suitable detector could be used in place of the ICP-OES system being used in the system currently under development by the Y-12 Plant. Consequently, MIPS may have the potential to perform real-time surface monitoring of beryllium although it was originally designed only for air surface monitoring. 


\subsubsection{Surface-Enhanced Raman Spectrometry}

Description - Raman spectrometry, occurs when incident light excites molecules in the sample which subsequently scatter light. While most of this scattered light is at the same wavelength as the incident light, some is scattered at a different wavelength. This inelastically scattered light is called Raman scatter. For a detailed description of SERS, please see Sect. 5.1.4.

Status - Raman spectroscopy has the potential to conduct both air and surface sample monitoring. Raman spectroscopy is rapid, nondestructive, and highly compound specific. This technique has multicomponent analysis potential and requires little sample preparation, which allows on-line and in-field analysis. (Vo-Dinh, T. 2000). Although SERS has the potential to perform real-time surface monitoring for beryllium, this technology is currently being sought to explore the possibility of developing a field portable device to measure $\mathrm{BeO}$ in air.

\subsubsection{Laser-Induced Breakdown Spectroscopy}

Description - LIBS works by firing a brief intense laser pulse to the surface of an object. The laser heats and vaporizes a small spot on the surface. A small telescope co-mounted with the laser captures light from the growing vapor and feeds it into the spectral analyzer. Elements create unique spectral signatures that signal their presence (Gustafson, J. 1999). Please see Sect. 5.1.3 for a detailed description on the LIBS technology.

Status - As of August 2000, the LANL LIBS-based beryllium smear monitoring instrument was nearly ready for limited field use. (Summary of Beryllium Monitoring Techniques Investigated).

This technology is well suited for survey applications. LIBS has a potential for conducting realtime surface beryllium monitoring for qualitative analysis.

The majority of experimental testing has been done on soil. Engineering details of decomposing a macroscopic organic matrix material are again of concern.

A LIBS-based device suitable for smear analysis is being developed by LANL where laboratory instruments have been fabricated and are in or near the field testing stage. The current intent at the LANL beryllium facility is to use the LANL LIBS smear monitor for qualitative survey purposes to, perhaps, reduce the work load on the ICP.

\subsubsection{Laser Ablation}

Description - Laser ablation is similar to LIBS in using a laser to deliver energy to a surface to be analyzed but, in the case of laser ablation, the laser serves only to ablate sample material into a gas stream which is directed to a primary ionization source such as ICP.

Status - The actual spectroscopy should provide superior sensitivity and reproducibility compared to LIBS-based techniques.

Engineering details of decomposing a macroscopic organic matrix material are of concern (Summary of Beryllium Monitoring Techniques Investigated). A laser ablation-based device suitable for smear analysis is currently not available nor does there appear to be much current interest by instrument manufacturers in developing such a device. 


\subsubsection{Absorptive Stripping Voltametry}

Description - ASV is a wet chemical spectroscopy. In the proposed design, a small quantity of solution is flushed through the filter with a predicted removal efficiency of at least $80 \%$ and charged to a small electrochemical cell in which the voltametry measurements are made.

Status - This technology has low machine cost and high sensitivity. The effects of interferences and the limited solubility of high-fired oxide have proven to be challenging during application of the technology. A recent unfavorable review has resulted in a loss of SBIR funding for the development of the device and the program is currently on hold. The unfavorable review centered on doubts that beryllium is actually dissolving or complexing to a significant degree in the solution that is being employed.

An instrument was near field ready; however, after the unfavorable review and the loss of funding, the program is currently on hold.

\subsubsection{Modified ICP}

Description - ICP technology is the present standard for beryllium surface sampling. This is considered the baseline technology. The current practice requires digestion of the entire smear sample to place it in liquid form. This liquid is then charged to an inductively coupled plasma where it is ionized. Spectroscopy can then be performed by a variety of methods, e.g., optical emission, atomic absorption, or mass.

Although the digestion procedure for refractory ceramics can be difficult and time consuming, ASO has developed a relatively rapid technique for the digestion of all beryllium compounds of interest, including high-fired oxide. Since a fairly general digestion technique is available, this phase of the process appears to be a good candidate for automation.

Status - This system is an accepted proven standard and users may be more willing to accept the results from a modification of a proven technology. The analytical technique is well developed and understood, detection limits are sufficient under current and expected requirements, cycle times are relatively short, and multi-element capability is available.

The potential challenges of the system are the fragility of the instrument, calibration concerns, waste generation, and argon consumption.

The add-on automation suite to be incorporated into the digestion technique will serve as the modification to the system.

\subsubsection{Gamma BeAST}

Description - The gamma BeAST analysis exploits the highly specific beryllium activation reaction to monitor bulk reactions.

Status - For this technology, little to no sample preparation is required. This is the principal beryllium monitoring technique used at the Rocky Flats Plant with many years of reliable service. 
Apparently being dissatisfied with sensitivity limitations, personnel at Rocky Flats are examining alternatives. There is limited detection range with this technology. Necessity for the highly active $(0.5 \mathrm{Ci})$ and relatively short-lived radioantimony $\left({ }^{124} \mathrm{Sb}\right)$ source is another drawback. 


\section{RECOMMENDATIONS}

1. Invest in technologies that have a high potential for performing both air and surface monitoring capabilities.

2. Utilize desired features listed in Table 1 and Table 2 for air and surface monitoring to evaluate new and emerging technologies.

3. Identify additional limitations and confounding variables and other possible metal interferences, for example titanium, and add to Tables 1 and 2.

4. Perform additional studies to determine if the technology could be further developed to include the capability to measure the particle size of airborne beryllium.

5. Perform additional studies to determine industrial workplace contaminants which can mask or interfere with surface monitoring such as dust, grease, and oils.

6. Utilize the EPA's Technology Verification Program once technologies have been developed for field portable devices to compare field portable device analysis results with laboratory results. This program is designed to accelerate the use of innovative technologies in the field and will provide unbiased measures of performance. (The Oak Ridger, August 22, 2000, ORNL Conducts Program for EPA). 


\section{LITERATURE AND REFERENCES CITED}

Steve Abeln, Los Alamos National Laboratory, Los Alamos, N.M., Personal Communication, August 23, 2000

Agency for Toxic Substances and Disease Registry. 1998. Public Health Statement, Beryllium ATSDR Public Health Statement, December 1988. Available from: http://www.atsdr.cdc.gov/ToxProfiles/phs8807, via the INTERNET. Accessed April 151998.

P. G. Datskos, S. Rajic, I. Datskou, C. E. Egert. "Infrared Micro-Caliorimetric Spectroscopy Using Uncooled Thermal Detectors", Imaging Spectroscopy III. Proceedings SPIE 3118, 280, 1997.

John Gustafson, Los Alamos National Laboratory, Los Alamos, N.M., News Release, Public Affairs Office, 99-045, March 18, 1999.

H. J. Hebert, 1999. Nuclear worker's payback. Available from: <http://abcnews.go.com/sections/us/DailyNews/nukeworkers990715.html>, via the INTERNET. Accessed January 31, 2000.

J. Miller, 1999. Beryllium: effect on worker health in Crystal City, VA. The Synergist. 10(11):5. Available from: http://www.aiha.org/syn/99index.html, via the INTERNET. Accessed April 14, 2000.

National Jewish Medical and Research Center. 1998. Beryllium disease: reducing the risks. Available from: <http://www.nationaljewish.org/beryllium/ber.htm>, via the INTERNET. Accessed January 18, 2000.

National Medical Services. 1997. Testing for beryllium. Available from: <http://www.nmslab.com/beryl.html>, via the INTERNET. Accessed January 18, 2000.

National Institute of Safety and Health Manual of Analytical Methods, "Lead in Surface Wipe Samples", 4th ed., August 15, 1994.

Paul Parson, "Beryllium Found in Y-12 Grinding Wheels", The Oak Ridger, August 10, 2000.

D. L. Renberger, and E. R. Hewitt, Fluor Daniel Hanford, Richland, Wash., "Initial Beryllium Characterization Report", September 29, 1999.

Rocky Flats Environmental Technology Site. February 3, 1997. Site Beryllium Characterization Sampling and Analysis Plan, Revision 0, Site Beryllium Characterization, 655-190.

Associated Press, St. Louis Post-Dispatch, "Ex-plant workers in KC are tested for toxic dust exposure”, June 19, 2000.

A. W. Stange, D. E. Hilmas, and F. J. Furman. "Possible health risks from low-level exposure to beryllium", Toxicology 111 213-224 (1996).

Tissue B. 1996. Spectroscopy. Available from: http://www.chem.ufl.edu/ itl/ 3417_s98/spectroscopy/aes.htm, via the INTERNET. Accessed April 1, 2000.

U.S. Department of Energy. 1999. Publication of the DOE chronic beryllium disease prevention program final rule (10 CFR 850). Memorandum for the Field Management Council. Washington, D.C. 
U.S. Department of Energy. 2000. About beryllium. Available from: <http://tisnt.eh.doe.gov/be/webdoc1.html-ssi>, via the INTERNET. Accessed February 29, 2000.

U.S. Department of Energy, Chronic Beryllium Disease Prevention Program Final Rule: Economic Analysis, November 19, 1999, P.1-2-1-3

U.S. Department of Energy, Chronic Beryllium Disease Prevention Program Final Rule: Economic Analysis, Office of Environment, Safety and Health, Office of Worker Health and Safety, November 19, 1999, (pp. 1-5).

U.S. Department of Energy, Federal Register. Volume 64. No. 235. December 8, 1999.

10 CFR Part 850, Docket No. EH-RM-98-BRYLM, RIN 1901-AA75, Office of Environment, Safety and Health, Department of Energy, I.B.

U.S. Department of Energy, Federal Register. Volume 64. No. 235. December 8, 1999.

10 CFR Part 850, Docket No. EH-RM-98-BRYLM, RIN 1901-AA75, Office of Environment, Safety and Health, Department of Energy, Supplemental Information I.A.

T. Vo-Dinh,UT-Battelle, Oak Ridge National Laboratory Proposal: Raman Spectroscopy for the Detection of Beryllium Oxide, April 2000.

T. Vo-Dinh and D. L. Stokes. "Surfaced-Enhanced Raman Vapor Dosimeter", Applied Spectroscopy 47(10),1728-1732 (1993). 


\section{CONTACT LIST}

MIPS Yixiang, Duan, Yoingyuam Su, Zhe Jim

Chemical Science and Technology Division

CST-9, MS K484

Los Alamos National Laboratory

Los Alamos, New Mexico 87545

Yduan@lanl.gov

Stephen P. Abeln

Material Science and Technology Division

MST-6, MS G770

Los Alamos National Laboratory

Los Alamos, New Mexico 87545

ABFLIPS Dr. Meng-Dawn Cheng

Oak Ridge National Laboratory

Environmental Sciences Division

Building 1505

MS 6038

Oak Ridge, Tennessee 37831-6038

Dr. Robert W. Smithwick

Y-12 National Security Complex

113C Union Valley Road

Oak Ridge, Tennessee 37830

CalSpec S. Rajic

Oak Ridge National Laboratory

P.O. Box 2009, MS 8039

Building 9102-2

Oak Ridge, Tennessee 37831-8039

(865) 574-9416

rajics@ornl.gov

P.G. Datskos

Oak Ridge National Laboratory

P.O. Box 2009, MS 8039

Building 9102-2

Oak Ridge, Tennessee 37831-8039

(865) 574-6205

datskpg@ornl.gov

LIBS Dr. David Cremers

Los Alamos National Laboratory

Group CLS-4 MS J567

Los Alamos, New Mexico 87545 


$\begin{array}{ll}\text { SERS } & \text { Tuan Vo-Dinh } \\ \text { Oak Ridge National Laboratory } \\ \text { Advanced Monitoring Development Group } \\ \text { P.O. Box 2008, 45005 } \\ \text { MS 6101 } \\ \text { Oak Ridge, Tennessee 37831-6101 } \\ \text { (865) 574-6249 } \\ \text { tvo@ornl.gov } \\ \\ \text { Bernard E. Phifer, Jr. } \\ \text { Y-12 National Security Complex } \\ \text { Building 9204-2, MS 8120 } \\ \text { Oak Ridge, Tennessee 37830 } \\ \text { (865) 576-7663 } \\ \text { phiferbejr@ Y12.doe.gov }\end{array}$




\section{$\underline{\text { Distribution }}$}

\section{BWXT Y-12}

(5) B. E. Phifer, Jr.

S. C. Laggis

W. T. Rogerson, Jr.

R. T. Ford

J. L. Jenkins, Jr.

J. P. Johnson

B. D. Johnston

J. P. Zonar

R. V. Carlson

K. R. Finney

S. R. Churnetski

E. L. Churnetski

M. L. Baker

M. L. Sollenberger

J. J. Reed, Jr.

L. E. Cooke

R. W. Smithwick

T. J. Oatts

\section{DOE}

L. R. Jones, YAO

Dave Weitzman, EH-52

James Slawski, DP-45

Paul Wambach, EH

\section{ORNL}

(2) M. L. Howell

M. Cheng

T. Vo-Dinh

\section{Pro-2-Serve}

(5) V. D. Smith

CDC-NIOSH

M. D. Hoover

Los Alamos National Laboratory

Dr. David Cremers

Dr. Xixiang Duan

\section{Kaiser-Hill}

Alec Cameron 